\title{
Impact of Obesity on Pediatric Acute Recurrent and Chronic Pancreatitis
}

\author{
Aliye Uc, MD ${ }^{1}$, M. Bridget Zimmerman, PhD $^{2}$, Michael Wilschanski, MBBS ${ }^{3}$, Steven L. \\ Werlin, MD ${ }^{4}$, David Troendle, MD ${ }^{5}$, Uzma Shah, MBBS $^{6}$, Sarah Jane Schwarzenberg, MD ${ }^{7}$, \\ Sue Rhee, MD $^{8}$, John F. Pohl, MD ${ }^{9}$, Emily R. Perito, MD $^{8}$, Joseph J. Palermo, MD ${ }^{10}$, Chee Y. \\ Ooi, MBBS, PhD ${ }^{11}$, Quin Liu, MD ${ }^{12}$, Tom K. Lin, MD ${ }^{10}$, Veronique D. Morinville, MD ${ }^{13}$, Brian \\ A. McFerron, MD $^{14}$, Sohail Z. Husain, MD $^{15}$, Ryan Himes, MD $^{16}$, Melvin B. Heyman, MD, \\ MPH $^{8}$, Tanja Gonska, MD ${ }^{17}$, Matthew J. Giefer, MD ${ }^{18}$, Cheryl E. Gariepy, MD ${ }^{19}$, Steven D. \\ Freedman, MD, PhD ${ }^{20}$, Douglas S. Fishman, MD ${ }^{16}$, Melena D. Bellin, MD , Bradley Barth, \\ MD $^{5}$, Maisam Abu-El-Haija, MD ${ }^{10}$, and Mark E. Lowe, MD, PhD ${ }^{21}$ \\ ${ }^{1}$ Stead Family Department of Pediatrics, University of lowa, Stead Family Children's Hospital, \\ lowa City, IA \\ ${ }^{2}$ Department of Biostatistics ${ }^{2}$, University of lowa, lowa City, IA \\ ${ }^{3}$ Department of Pediatrics, Hadassah Hebrew University Hospital, Jerusalem, Israel \\ ${ }^{4}$ Department of Pediatrics, Medical College of Wisconsin, Milwaukee, WI \\ ${ }^{5}$ Department of Pediatrics, University of Texas Southwestern Medical School, Dallas, TX \\ ${ }^{6}$ Department of Pediatrics, Massachusetts General Hospital for Children, Harvard Medical School, \\ Boston, MA \\ ${ }^{7}$ Department of Pediatrics, University of Minnesota Masonic Children's Hospital, Minneapolis, MN \\ ${ }^{8}$ Department of Pediatrics, University of California San Francisco, San Francisco, CA \\ ${ }^{9}$ Department of Pediatrics, University of Utah, Salt Lake City, UT \\ ${ }^{10}$ Department of Pediatrics, Cincinnati Children's Hospital Medical Center, Cincinnati, $\mathrm{OH}$ \\ ${ }^{11}$ Department of Pediatrics, School of Women's and Children's Health, Medicine, University of \\ New South Wales and Sydney Children's Hospital, Randwick Sydney, Australia \\ ${ }^{12}$ Department of Pediatrics, Cedars-Sinai Medical Center, Los Angeles, CA \\ ${ }^{13}$ Department of Pediatrics, Montreal Children's Hospital, McGill University, Montreal, QC, \\ Canada
}

Corresponding author: Aliye Uc, MD, Stead Family Department of Pediatrics, University of Iowa Health Care, 200 Hawkins Drive, BT 1120-C, Iowa City, IA 5224 aliye-uc@uiowa.edu).319.356.2950.

Conflicts: Dr. Mark Lowe is on the Board of Directors of the National Pancreas Association; receives royalties from Millipore Inc and UpToDate. Dr. Tanja Gonska received a research grant from Vertex Pharmaceuticals. Dr. John Pohl is on the speaker's bureau for Medical Education Resources, Inc.; Dr. Melena Bellin is a consultant for AbbVie Inc and ARIEL Precision Medicine. Dr. Aliye Uc is a member of American Board of Pediatrics, Subboard of Pediatric Gastroenterology. The other authors declare no conflicts of interest.

All authors are responsible for reported research. They have participated in the concept and design; collection, analysis and interpretation of data; writing and revising of the manuscript, and decision to submit the manuscript for publication. 
${ }^{14}$ Department of Pediatrics, Riley Hospital for Children, Indiana University School of Medicine, Indianapolis, IN

${ }^{15}$ Department of Pediatrics, Children's Hospital of Pittsburgh, Pittsburgh, PA

${ }^{16}$ Department of Pediatrics, Baylor College of Medicine, Houston, TX

${ }^{17}$ Department of Pediatrics, Hospital for Sick Children, Toronto, ON, Canada

${ }^{18}$ Department of Pediatrics, Seattle Children's Hospital, Seattle, WA

${ }^{19}$ Department of Pediatrics, Nationwide Children's Hospital, Columbus, $\mathrm{OH}$

${ }^{20}$ Department of Internal Medicine, Harvard Medical School, Boston, MA

${ }^{21}$ Department of Pediatrics, Washington University School of Medicine, St. Louis, MO

\section{Abstract}

Objective-To assess the impact of obesity on pediatric acute recurrent pancreatitis (ARP) or chronic pancreatitis $(\mathrm{CP})$.

Methods-We determined body mass index (BMI) status at enrollment in INSPPIRE

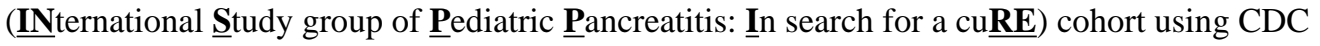
criteria for pediatric-specific BMI percentiles. We used Cochran-Armitage to assess trends, Jonckheere-Terpstra to determine associations.

Results-Of 446 subjects (ARP = 241, CP = 205), 22 were underweight, 258 normal weight, 75 overweight, 91 obese. The BMI groups were similar in sex, race, age at presentation. Hypertriglyceridemia was more common in overweight or obese. Obese children were less likely to have $\mathrm{CP}$ and more likely to have acute inflammation on imaging. Compared to children with normal weight, obese or overweight were older at first acute pancreatitis (AP) episode and diagnosed with $\mathrm{CP}$ at an older age. Obese or overweight were less likely to undergo medical or endoscopic treatment, develop exocrine pancreatic insufficiency, require total pancreatectomy with islet autotransplantation (TPIAT). Diabetes was similar among all groups.

Conclusions-Obesity or overweight seems to delay the initial AP episode and diagnosis of CP compared to normal weight or underweight. The impact of obesity on pediatric $\mathrm{CP}$ progression and severity deserves further study.

\section{Keywords}

Children; Body Mass Index; Pancreatitis

\section{INTRODUCTION}

Within the last decade, pediatricians have observed an increased incidence of children with acute pancreatitis (AP). ${ }^{1-5}$ In general, children with AP recover without long-term sequelae, but a subset has recurrent attacks of AP (defined as acute recurrent pancreatitis or ARP); some develop chronic pancreatitis $(\mathrm{CP}) .{ }^{6} \mathrm{CP}$ is characterized by irreversible structural damage in the pancreas, fibrotic replacement of the parenchyma and finally failure of both exocrine and endocrine functions. ${ }^{6}$ In children, genetic risk factors play a major role in 
recurrent pancreatic inflammation and progression to chronic disease. ${ }^{7-10}$ This is in contrast to adult $\mathrm{CP}$, where environmental factors (namely alcohol and tobacco) pose the most significant risk. ${ }^{11,12}$ As with adults, ${ }^{13}$ ARP most likely precedes CP in children. ${ }^{14}$ Importantly, children with CP carry significant disease and socioeconomic burden, $7,8,10,15$ underscoring the importance of identifying predisposing factors early to avoid progression of ARP to CP.

Obesity is an important risk factor for severe AP in adults. Obese patients with AP are prone to more severe inflammation with high morbidity and mortality, as well as local and systemic complications, compared to patients with normal weight. ${ }^{16-20}$ It is not clear whether obesity is also a risk factor for the development of acute recurrent pancreatitis or chronic pancreatitis, in adults or children. A single prospective study in adult patients, reported a greater presence of overweight or obesity compared to normal controls before disease onset of alcoholic CP. Interestingly, the only impact in this alcoholic pancreatitis cohort with obesity was delayed progression to $\mathrm{CP}$ if they had prior history of pancreatic surgery. ${ }^{21}$

In this report, we studied the impact of overweight or obesity on pediatric pancreatic disease characteristics in our well-phenotyped INSPPIRE (INternational $\underline{\text { Study group of }}$ Pediatric Pancreatitis: In search for a cuRE) cohort of children with ARP and CP. ${ }^{22}$

\section{MATERIALS AND METHODS}

\section{Study Design and Participants}

Demographic and clinical information were collected at the time of enrollment of children who fulfilled the criteria for ARP and CP from 18 pediatric academic medical centers. INSPPIRE study design and enrollment criteria have been previously described. ${ }^{22}$ All patients were $<19$ years of age at the time of enrollment. As previously defined, ARP diagnosis required 2 episodes of AP along with resolution of pain ( $\geq 1$ month between episodes) or normalization of pancreatic enzymes and resolution of pain in between episodes irrespective of time interval. ${ }^{6}$ Diagnosis of $\mathrm{CP}$ required at least one of the following: (a) abdominal pain plus imaging findings suggestive of chronic pancreatic damage; (b) exocrine pancreatic insufficiency and imaging findings; (c) endocrine pancreatic insufficiency and imaging findings. ${ }^{6}$ Weight and height measurements were collected from physician questionnaires. Centers for Disease Control and Prevention (CDC) Growth Charts and pediatric age- and gender-specific body mass index (BMI) percentiles to classify children as underweight $\left(<5^{\text {th }}\right.$ percentile), normal weight $\left(5^{\text {th }}-<85^{\text {th }}\right.$ percentile), overweight $\left(85^{\text {th }}-<95^{\text {th }}\right.$ percentile), or obese ( $\geq 95^{\text {th }}$ percentile). ${ }^{23}$ Diabetes mellitus was defined by 2006 WHO criteria as fasting glucose $\geq 7.0 \mathrm{mmol} / \mathrm{L}(126 \mathrm{mg} / \mathrm{dL}$ ) or plasma glucose $\geq 11.1 \mathrm{mmol} / \mathrm{L}$ (200 $\mathrm{mg} / \mathrm{dL}$ ) 2 hours after glucose load of $1.75 \mathrm{~g} / \mathrm{kg}$ children (to maximum $75 \mathrm{~g}$ glucose load) or elevated $\mathrm{HbA} 1 \mathrm{c}$ over $6.5 \%$ or $48 \mathrm{mmol} / \mathrm{mol}^{24}$ Clinical and demographic data were entered into the REDCap ${ }^{\mathrm{TM}}$ (Research Electronic Data Capture, Vanderbilt University, Nashville, Tenn) database at 18 centers from September 2012 to March 2017, through standardized patient and physician questionnaires and represented baseline information of the INSPPIRE cohort. All centers obtained Institutional Review Board approval or the equivalent for their 
country for this study. Most of the 446 patients included in this study have been previously reported. $7,8,15$

\section{Statistical Analysis}

Summary statistics use mean with standard deviation (SD) or median with interquartile range (IQR) according to the normality of distribution. Categorical variables were analyzed using Cochran-Armitage trend test to examine whether prevalence of findings increased/ decreased with BMI. The Jonckheere-Terpstra test was used to assess the association between BMI and levels of pain and missed school days. A $P$ value $<0.05$ was considered statistically significant.

\section{RESULTS}

\section{Patient Characteristics}

A total of 446 INSPPIRE subjects were reviewed with 241 having ARP and 205 having CP. Of these patients, 22 (4.9\%) were underweight, 258 were normal weight (57.8\%), 75 (16.8\%) were overweight, and 91 were obese (20.4\%) based on BMI. Demographics of the cohorts are shown in Table 1. The groups were not different in age at first diagnosis of AP, sex or race, but obese children were more likely to be of Hispanic ethnicity $(P=0.002)$. The distribution of BMI at centers with a high prevalence of Hispanic children (Children's Hospital of Los Angeles, UCSF, UTSW, Baylor) were not different when compared to other centers $(P=0.94)$.

\section{Risk Factors of ARP and CP Per BMI Groups}

Table 2 shows the distribution of risk factors for ARP and $\mathrm{CP}$ among the groups. Patients with normal BMI were more likely to have cationic trypsinogen (PRSS1) mutations ( $P=$ $0.05)$. There were no differences among the groups for mutations in serine protease inhibitor Kazal-type 1 (SPINK1), cystic fibrosis transmembrane conductance regulator (CFTR), or chymotrypsin $C(C T R C)$. Hypertriglyceridemia (as defined by treating physician) was found almost exclusively in overweight or obese patients $(P=0.02)$. Other risk factors, including obstructive risk factors were not different among the groups.

\section{Diagnosis of CP Per BMI Groups}

Obese or overweight children were less likely to have $\mathrm{CP}(P=0.009)$ and were diagnosed with first AP attack and with $\mathrm{CP}$ at an older age than normal weight or underweight children $(P=0.01)$ (Table 3$)$. Imaging findings were determined by endoscopic retrograde cholangiopancreatography (ERCP), magnetic resonance imaging (MRI)/magnetic resonance cholangiopancreatography (MRCP); computed tomography (CT) or endoscopic ultrasound (EUS). Acute inflammatory changes, such as gland enlargement, peripancreatic inflammation/fat stranding consistent with AP/ARP were more commonly found in overweight or obese children $(P<0.01)$. Chronic changes indicative of $\mathrm{CP}$ (pancreatic atrophy, pancreatic fibrosis, pancreatic duct irregularity, pancreatic duct dilatation, pancreatic duct stone, calcifications, abnormal side branches) were found at similar rates in all groups (Table 4). The exception was pancreatic ductal strictures which were significantly 
less common in obese or overweight $(P=0.008)$ (Table 4$)$. Overweight or obese children were also less likely to have ERCP done for diagnostic or therapeutic purposes $(P=0.03)$.

\section{Impact of Weight Category on Disease Burden and Complications of CP}

Weight category had no impact on the frequency or pattern of abdominal pain, missed school days, emergency room visits or hospitalizations related to pancreatitis (Table 5). Obese children were significantly less likely to undergo medical treatments (specifically pancreatic enzyme therapy), endoscopic interventions and total pancreatectomy/islet autotransplantation (TPIAT) than other groups ( $P<0.001,0.01$, and 0.002 respectively) (Table 6). Finally, overweight or obese children were less likely to have exocrine pancreatic insufficiency $(P=0.013)$ and there were no differences in the diagnosis of diabetes among the groups (Table 7).

\section{Findings Controlling for Hispanic Ethnicity}

Because Hispanic ethnicity is associated with obesity, we performed additional analysis of the parameters associated with obesity to control for Hispanic ethnicity. These showed that the same trends persisted in the study sub-population of non-Hispanics as in the entire cohort (see Supplemental Table 1).

\section{DISCUSSION}

In this large, multicenter and multinational cohort of children with acute recurrent pancreatitis, we found that overweight or obese children were less likely to suffer from chronic pancreatitis, exocrine pancreatic insufficiency and less likely to undergo medical therapies, endoscopic procedures or TPIAT.

Obesity is a well-recognized risk factor of severe AP in adults, associated with high morbidity and mortality. ${ }^{16-20}$ During AP episodes, obese patients may be prone to both local complications (i.e. pancreatic pseudocyst, necrosis or abscess), systemic complications (sepsis, lung and kidney failure) and increased risk of death. Increased risk of local complications may be related to greater volume of retroperitoneal, peripancreatic or intrapancreatic fat found in obese people with $\mathrm{AP},{ }^{20,25,26}$ as fat will have a higher propensity for necrosis. Indeed, there is a direct correlation between BMI, amount of intrapancreatic fat and severity of AP. ${ }^{20}$ The mechanisms leading to higher levels of complications of AP in obesity are not well-understood. A recent study has suggested that unsaturated fatty acids released from intrapancreatic fat could be responsible of local necrosis and systemic complications. ${ }^{20}$ Similar to adults, obese children with AP have worse outcomes compared to non-obese: severe AP, length of stay, medical costs, mortality are significantly higher in obese individuals. ${ }^{27}$

The role of obesity as a risk factor for ARP or CP is largely unknown. In a study by Ammann et al, progression to CP in a group of adult patients was slower over time if BMI was $>25$ and they underwent a drainage surgery previously. ${ }^{21}$ However, it should be noted that this was a cohort of alcoholic $\mathrm{CP}$ patients, about half of patients were obese and the effect was not seen in obese patients without prior surgical history. The outcome may be 
quite different in the pediatric cohort where alcohol is a negligible risk factor of ARP and $\mathrm{CP}^{7,8}$

In our cohort, obese or overweight children were diagnosed with $\mathrm{CP}$ at an older age and their imaging findings were overwhelmingly supportive of acute inflammatory changes in the pancreas. These data suggest that obesity may induce a delayed-onset disease, a prolonged proinflammatory state, with delayed progression to a chronic inflammatory state. According to the popular sentinel acute pancreatitis event (SAPE) hypothesis or repeated inflammation-recovery-fibrosis theory, massive inflammatory response develops with AP consistent of both early and late phases. ${ }^{28}$ Initially inflammation in the pancreas attracts inflammatory cells (neutrophils, lymphocytes) along with cytokines and causes oxidative stress. ${ }^{28}$ During later phases of the inflammation, profibrotic cells and stellate cells predominate. Once the inciting factor is removed, the pancreas heals to baseline, but recurrent inflammation sets the stage for progressive fibrosis. It is possible that the peri- or intrapancreatic fat creates a proinflammatory or prooxidant state that prevents or delays the transition to chronicity. We have not analyzed the pancreatic imaging studies to verify the presence of pancreatic fat in our patients. This will be an important addition to the study questionnaires as the INSPPIRE consortium moves forward.

Although diagnosis of $\mathrm{CP}$ was less common in obese or overweight children, the only significant difference between the groups was the presence of ductal strictures in children with normal weight. It is possible that differences could be detected in a larger cohort.

The high percentage of obese children in our population reflects the increased prevalence of obesity in the US and other countries observed within the last few decades. ${ }^{29,30}$ Twentythree percent of our study population was obese, which is a slightly higher than expected US prevalence for this age group. ${ }^{29}$ We observed a much higher percentage of Hispanic children with obesity in our cohort $(40 \%)$ compared to the general US population $(<24 \%$ for all Hispanic pediatric age groups). ${ }^{29}$ This raises an interesting question about the potential role of genetic variations among ethnic groups in disease presentation or evolution. The distribution of BMI was similar at all centers including centers that enrolled a higher number of Hispanic children, therefore it is unlikely that the results were skewed by an enrollment bias.

Obese children were less likely to have exocrine pancreatic insufficiency diagnosis. They were less likely to receive medical treatments (specifically pancreatic enzyme therapy), endoscopic or surgical procedures, such as TPIAT. TPIAT is directed primarily to the treatment of $\mathrm{CP}$ by removing the pancreas that has lost its exocrine function while attempting to preserve its islet cell mass and maintain the endocrine function. ${ }^{31}$

Hypertriglyceridemia is known to be associated with acute pancreatitis, ${ }^{32,33}$ and a recent study in adults has shown that even mild elevations in serum triglycerides may be a risk factor. ${ }^{34}$ Elevated serum triglycerides are well-described in obese children as a risk factor for cardiovascular disease. ${ }^{35,36} \mathrm{It}$ is possible that elevated triglyceride levels in our cohort of overweight or obese children is due to obesity and unrelated to pancreatitis. 
We did not observe different rates of diabetes among the groups, but diabetes is a late complication of $\mathrm{CP}\left(18 \%, 20\right.$ years after diagnosis). ${ }^{37}$ It may be too early to observe diabetes in our cohort. Overall, the percentage of children with diabetes in our cohort (7.0\%; 95\% confidence interval, $5 \%-10 \%$ ) was higher than that observed in the US population $\left(0.25-0.5 \%\right.$ under the age 20 years old). ${ }^{38-40}$ Our report of diabetes is based on physician's diagnosis and does not differentiate between the types of diabetes, including Type 1,2, or Type 3c (pancreatogenic) diabetes, therefore it is possible that it was under-reported. Type $3 c$ diabetes is emerging as a distinct form of diabetes, although there are yet no clear guidelines to differentiate it from other forms of diabetes. ${ }^{41,42}$ Our future efforts will include a detailed phenotyping of patients for all types of diabetes, including prediabetes.

Obesity or overweight present with the initial AP attack later and are diagnosed with CP later compared to normal weight or underweight. In the INSPPIRE cohort, overweight or obese children were less likely than normal weight or underweight children to suffer from chronic pancreatitis, exocrine pancreatic insufficiency and undergo medical therapies, endoscopic procedures or TPIAT. The full impact of obesity on pediatric pancreatitis severity, recurrence, progression and chronicity will only become clear with longer followup of our cohort.

\section{Supplementary Material}

Refer to Web version on PubMed Central for supplementary material.

\section{Acknowledgments}

Funding: Dr. Aliye Uc is supported by the National Institute of Health grants (R21 DK096327, U01 DK108334, R01 DK097820); INSPPIRE registry was developed by CTSA (2UL1 TR000442) and REDCap.

\section{References}

1. Morinville VD, Barmada MM, Lowe ME. Increasing incidence of acute pancreatitis at an American pediatric tertiary care center: is greater awareness among physicians responsible? Pancreas. 2010; 39:5-8. [PubMed: 19752770]

2. Nydegger A, Heine RG, Ranuh R, et al. Changing incidence of acute pancreatitis: 10-year experience at the Royal Children's Hospital, Melbourne. J Gastroenterol Hepatol. 2007; 22:13131316. [PubMed: 17489962]

3. Lopez MJ. The changing incidence of acute pancreatitis in children: a single-institution perspective. J Pediatr. 2002; 140:622-624. [PubMed: 12032533]

4. Pant C, Deshpande A, Olyaee M, et al. Epidemiology of acute pancreatitis in hospitalized children in the United States from 2000-2009. PLoS One. 2014; 9:e95552. [PubMed: 24805879]

5. Pant C, Deshpande A, Sferra TJ, et al. Emergency department visits for acute pancreatitis in children: results from the Nationwide Emergency Department Sample 2006-2011. J Investig Med. 2015; 63(4):646-648.

6. Morinville VD, Husain SZ, Bai H, et al. Definitions of pediatric pancreatitis and survey of present clinical practices. J Pediatr Gastroenterol Nutr. 2012; 55:261-265. [PubMed: 22357117]

7. Schwarzenberg SJ, Bellin M, Husain SZ, et al. Pediatric chronic pancreatitis is associated with genetic risk factors and substantial disease burden. J Pediatr. 2015; 166:890-896. e891. [PubMed: 25556020] 
8. Kumar S, Ooi CY, Werlin S, et al. Risk Factors Associated With Pediatric Acute Recurrent and Chronic Pancreatitis: Lessons From INSPPIRE. JAMA pediatrics. 2016; 170:562-569. [PubMed: 27064572]

9. Witt H, Beer S, Rosendahl J, et al. Variants in CPA1 are strongly associated with early onset chronic pancreatitis. Nat Genet. 2013; 45:1216-1220. [PubMed: 23955596]

10. Giefer MJ, Lowe ME, Werlin SL, et al. Early-Onset Acute Recurrent and Chronic Pancreatitis Is Associated with PRSS1 or CTRC Gene Mutations. J Pediatr. 2017; 186:95-100. [PubMed: 28502372]

11. Ye X, Lu G, Huai J, et al. Impact of smoking on the risk of pancreatitis: a systematic review and meta-analysis. PLoS One. 2015; 10:e0124075. [PubMed: 25879541]

12. Cote GA, Yadav D, Slivka A, et al. Alcohol and smoking as risk factors in an epidemiology study of patients with chronic pancreatitis. Clin Gastroenterol Hepatol. 2011; 9:266-273. quiz e227. [PubMed: 21029787]

13. Whitcomb DC, Frulloni L, Garg P, et al. Chronic pancreatitis: An international draft consensus proposal for a new mechanistic definition. Pancreatology. 2016; 16:218-224. [PubMed: 26924663]

14. Taylor CJ, Chen K, Horvath K, et al. ESPGHAN and NASPGHAN Report on the Assessment of Exocrine Pancreatic Function and Pancreatitis in Children. J Pediatr Gastroenterol Nutr. 2015; 61:144-153. [PubMed: 25915425]

15. Ting J, Wilson L, Schwarzenberg SJ, et al. Direct Costs of Acute Recurrent and Chronic Pancreatitis in Children in the INSPPIRE Registry. J Pediatr Gastroenterol Nutr. 2016; 62:443449. [PubMed: 26704866]

16. Tsai CJ. Is obesity a significant prognostic factor in acute pancreatitis? Dig Dis Sci. 1998; 43:2251-2254. [PubMed: 9790461]

17. Papachristou GI, Papachristou DJ, Avula H, et al. Obesity increases the severity of acute pancreatitis: performance of APACHE-O score and correlation with the inflammatory response. Pancreatology. 2006; 6:279-285. [PubMed: 16636600]

18. Premkumar R, Phillips AR, Petrov MS, et al. The clinical relevance of obesity in acute pancreatitis: targeted systematic reviews. Pancreatology. 2015; 15:25-33. [PubMed: 25464938]

19. Krishna SG, Hinton A, Oza V, et al. Morbid Obesity Is Associated With Adverse Clinical Outcomes in Acute Pancreatitis: A Propensity-Matched Study. Am J Gastroenterol. 2015; 110:1608-1619. [PubMed: 26482857]

20. Navina S, Acharya C, DeLany JP, et al. Lipotoxicity causes multisystem organ failure and exacerbates acute pancreatitis in obesity. Sci Transl Med. 2011; 3:107ra110.

21. Ammann RW, Raimondi S, Maisonneuve P, et al. Is obesity an additional risk factor for alcoholic chronic pancreatitis? Pancreatology. 2010; 10:47-53. [PubMed: 20332661]

22. Morinville VD, Lowe ME, Ahuja M, et al. Design and implementation of INSPPIRE. J Pediatr Gastroenterol Nutr. 2014; 59:360-364. [PubMed: 24824361]

23. Himes JH, Dietz WH. Guidelines for overweight in adolescent preventive services: recommendations from an expert committee. The Expert Committee on Clinical Guidelines for Overweight in Adolescent Preventive Services. Am J Clin Nutr. 1994; 59:307-316. [PubMed: 8310979]

24. Report of the Expert Committee on the Diagnosis and Classification of Diabetes Mellitus. Diabetes Care. 1997; 20:1183-1197. [PubMed: 9203460]

25. Beger HG, Bittner R, Block S, et al. Bacterial contamination of pancreatic necrosis. A prospective clinical study. Gastroenterology. 1986; 91:433-438. [PubMed: 3522342]

26. Leger L, Chiche B, Louvel A. Pancreatic necrosis and acute pancreatitis. World J Surg. 1981; 5:315-317. [PubMed: 7293193]

27. Murata A, Ohtani M, Muramatsu K, et al. Impact of obesity on outcomes of paediatric acute pancreatitis based on a national administrative database. Pediatric obesity. 2016; 11:174-180. [PubMed: 26061540]

28. Whitcomb DC. Hereditary pancreatitis: new insights into acute and chronic pancreatitis. Gut. 1999; 45:317-322. [PubMed: 10446089] 
29. Ogden CL, Carroll MD, Lawman HG, et al. Trends in Obesity Prevalence Among Children and Adolescents in the United States, 1988-1994 Through 2013-2014. JAMA. 2016; 315:2292-2299. [PubMed: 27272581]

30. Wang Y, Lobstein T. Worldwide trends in childhood overweight and obesity. International journal of pediatric obesity : IJPO : an official journal of the International Association for the Study of Obesity. 2006; 1:11-25.

31. Azhari H, Rahhal R, Uc A. Is Total Pancreatectomy with Islet Autotransplantation A Reasonable Choice for Pediatric Pancreatitis? Jop. 2015; 16:335-341. [PubMed: 26523129]

32. Balanescu NR, Topor L, Ulici A, et al. Acute pancreatitis secondary to hyperlipidemia in an 11year-old girl: a case report and review of literature. Journal of medicine and life. 2013; 6:2-6. [PubMed: 23599811]

33. Yadav D, Pitchumoni CS. Issues in hyperlipidemic pancreatitis. J Clin Gastroenterol. 2003; 36:5462. [PubMed: 12488710]

34. Pedersen SB, Langsted A, Nordestgaard BG. Nonfasting Mild-to-Moderate Hypertriglyceridemia and Risk of Acute Pancreatitis. JAMA Intern Med. 2016; 176:1834-1842. [PubMed: 27820614]

35. Guillaume M, Lapidus L, Beckers F, et al. Cardiovascular risk factors in children from the Belgian province of Luxembourg. The Belgian Luxembourg Child Study. Am J Epidemiol. 1996; 144:867880. [PubMed: 8890665]

36. Reis EC, Kip KE, Marroquin OC, et al. Screening children to identify families at increased risk for cardiovascular disease. Pediatrics. 2006; 118:e1789-e1797. [PubMed: 17142500]

37. Howes N, Lerch MM, Greenhalf W, et al. Clinical and genetic characteristics of hereditary pancreatitis in Europe. Clin Gastroenterol Hepatol. 2004; 2:252-261. [PubMed: 15017610]

38. Prevention CfDCa. Services USDoHaH. National Diabetes Statistics Report: Estimates of Diabetes and Its Burden in the United States, 2014. Atlanta, GA: 2014.

39. Duncan GE. Prevalence of diabetes and impaired fasting glucose levels among US adolescents: National Health and Nutrition Examination Survey, 1999-2002. Archives of pediatrics \& adolescent medicine. 2006; 160:523-528. [PubMed: 16651496]

40. Dolan LM, Bean J, D'Alessio D, et al. Frequency of abnormal carbohydrate metabolism and diabetes in a population-based screening of adolescents. J Pediatr. 2005; 146:751-758. [PubMed: 15973311]

41. Rickels MR, Bellin M, Toledo FG, et al. Detection, evaluation and treatment of diabetes mellitus in chronic pancreatitis: recommendations from PancreasFest 2012. Pancreatology. 2013; 13:336-342. [PubMed: 23890130]

42. Uc A, Andersen DK, Bellin MD, et al. Chronic Pancreatitis in the 21st Century - Research Challenges and Opportunities: Summary of a National Institute of Diabetes and Digestive and Kidney Diseases Workshop. Pancreas. 2016; 45:1365-1375. [PubMed: 27748719] 


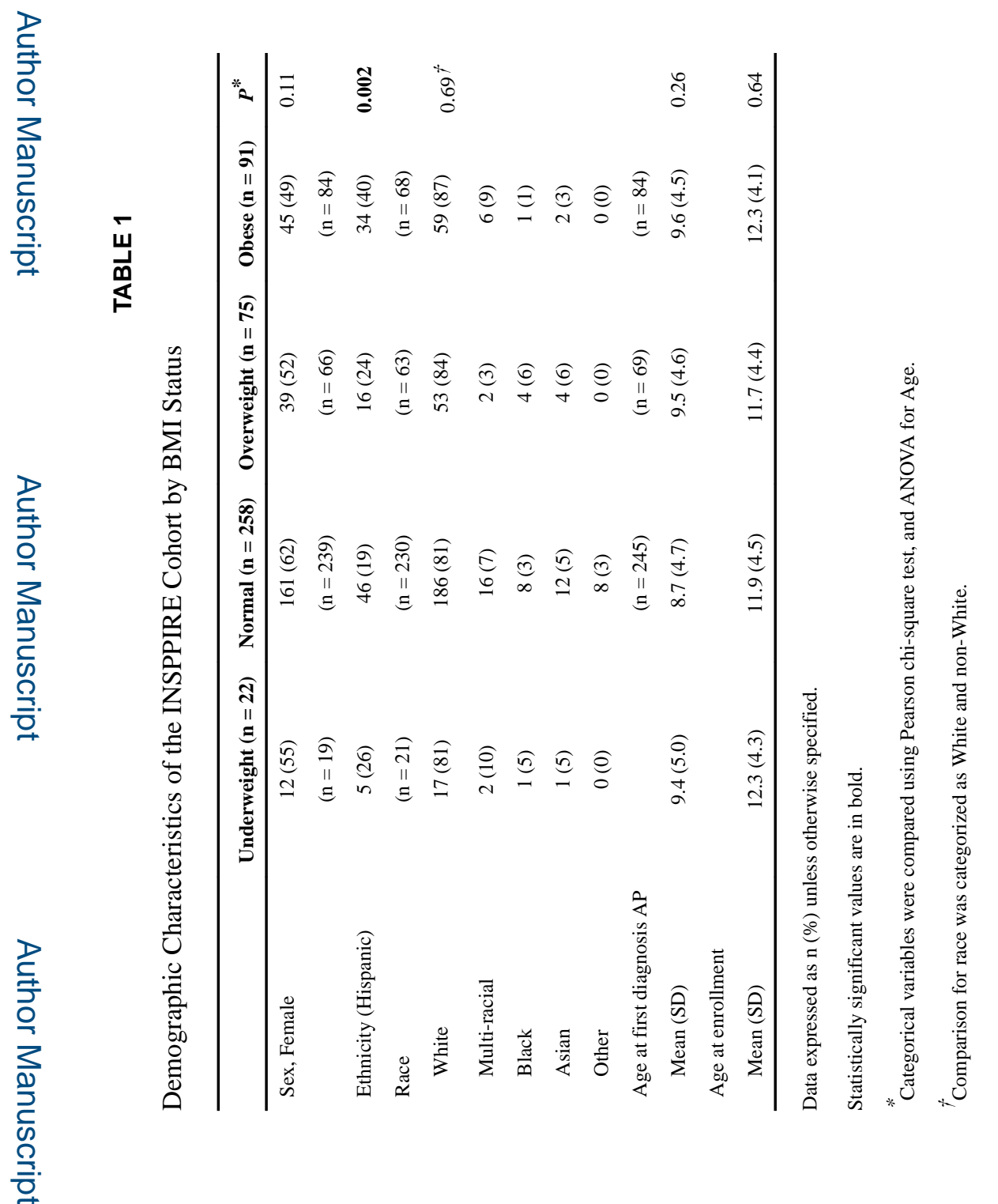

Pancreas. Author manuscript; available in PMC 2019 September 01. 


\section{롤 \\ 골}

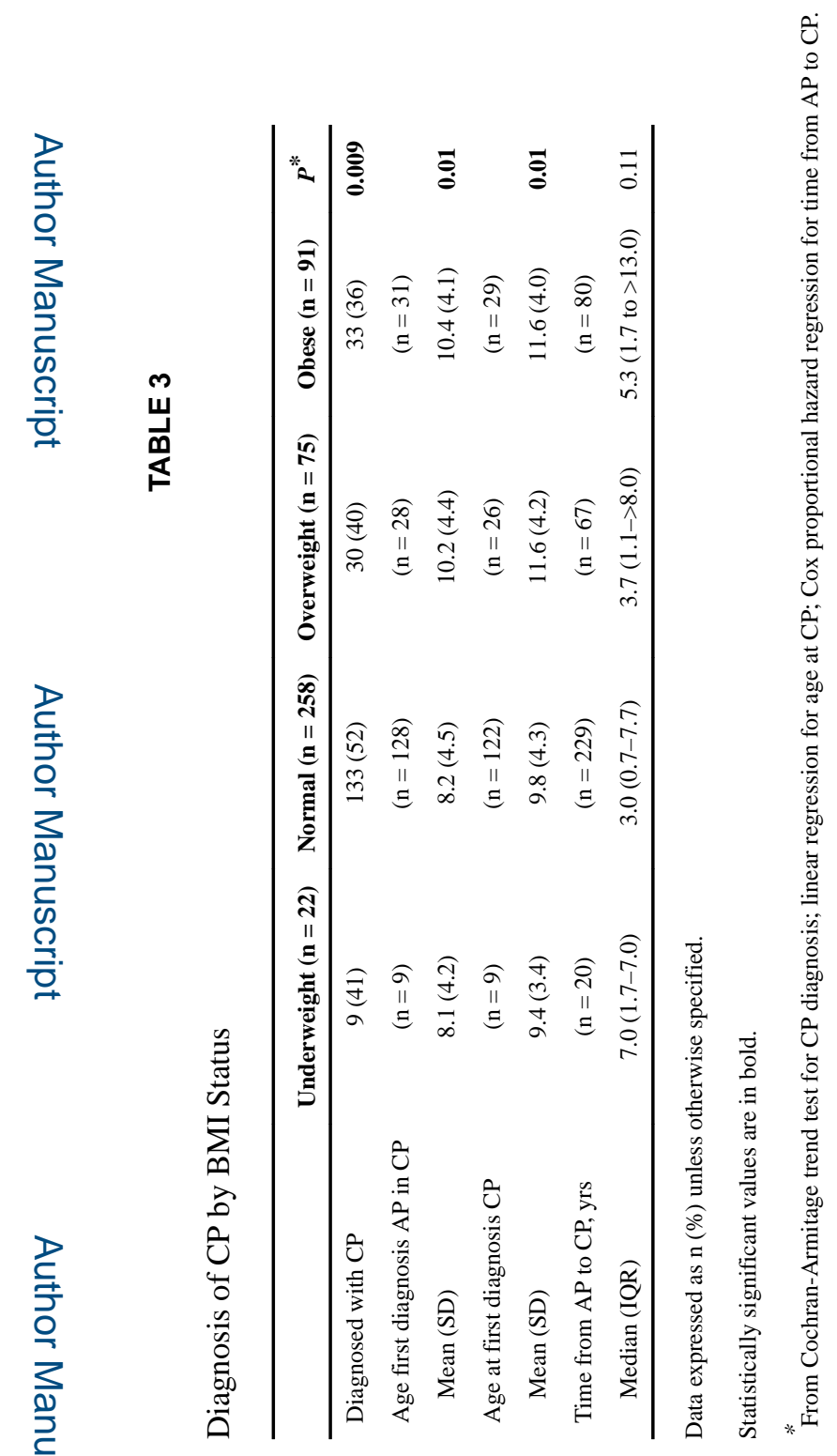




\section{을 \\ 졸}

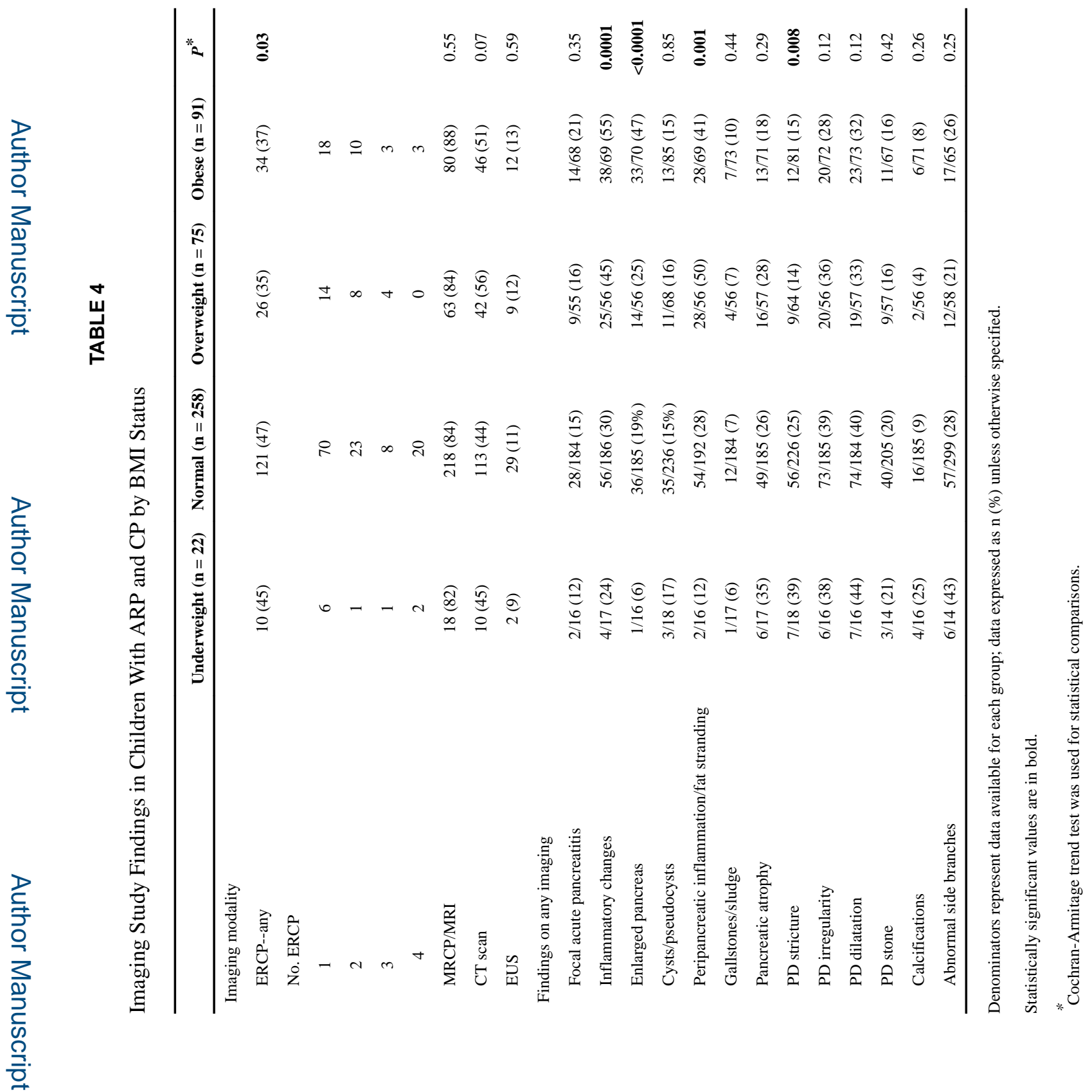

Pancreas. Author manuscript; available in PMC 2019 September 01. 


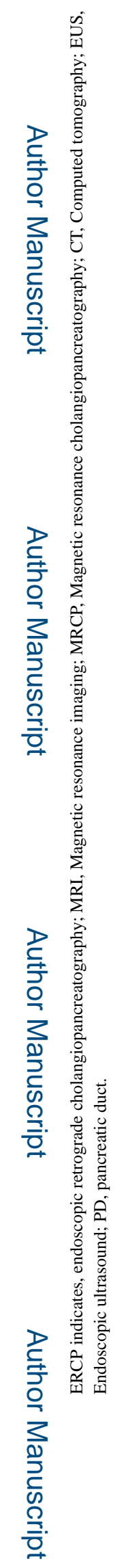




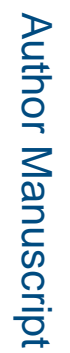

ב

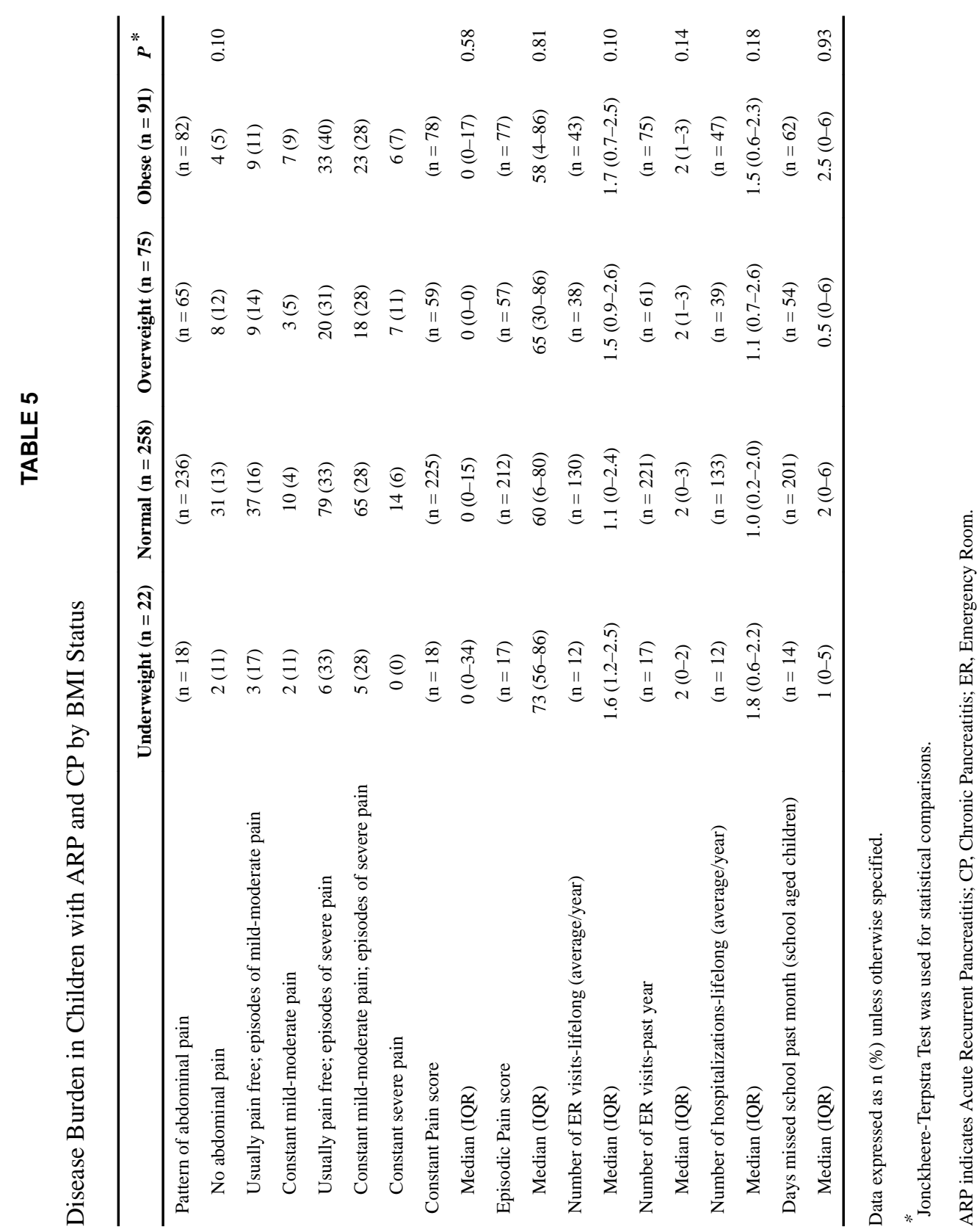

Pancreas. Author manuscript; available in PMC 2019 September 01. 

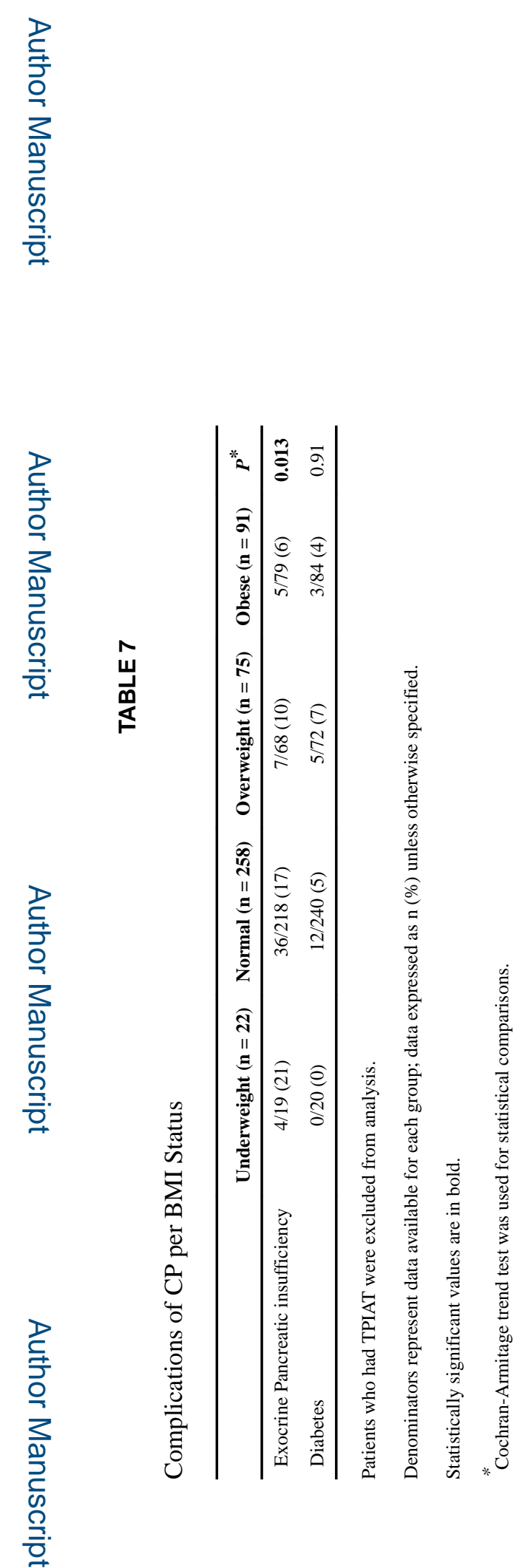

Pancreas. Author manuscript; available in PMC 2019 September 01. 